\title{
The Obesity epidemic and Cancer in India - The Cochin Cancer Research Centre initiative
}

\author{
Prem Ravi Varma PK ${ }^{1 *}$, Ushasree Warrier ${ }^{2}$, Jaisy Joseph ${ }^{3}$, Jancymol Isac ${ }^{3}$, Anvar Sadath ${ }^{3}$, Silji K Isac ${ }^{3}$, Prasanth M \\ $\mathbf{K}^{3}$, Sreelakshmi Madhu ${ }^{3}$
}

${ }^{1}$ Department of Medical Oncology, Cochin Cancer Research Centre, India

${ }^{2}$ Department of Radiation Oncology, Cochin Cancer Research Centre, India

${ }^{3}$ Cochin Cancer Research Centre, Government Medical College Compound, India

*Corresponding author: Prem Ravi Varma PK, Department of Medical Oncology, Cochin Cancer Research Centre, India

\begin{abstract}
India is a developing country which is in a transitional state of under nutrition due to poverty and obesity due to the industrialization and rapid urbanization. In India, more than 135 million individuals are affected by obesity. Urban population and states with high socio-economic status were found to be having higher obesity prevalence. According to ICMR-INDIAB study 2015, prevalence rate of obesity and central obesity vary from $11.8 \%$ to $31.3 \%$ and $16.9 \%-36.3 \%$ respectively. Obesity is one of the main medical and financial burdens for the government. This problem of obesity can be preventable by spreading public awareness about obesity and its health consequences. Governmental agencies should promote the benefits of healthy lifestyle, food habits and physical activity. Obesity is a risk factor for cancer. This is a root and branch review of obesity and cancer.
\end{abstract}

\section{Introduction}

Obesity is not a new disease. The Palaeolithic sculptor of the Venus of Willendorf (Figure 1), working about 25,000 years ago, cannot have rendered the shape of a very obese female so perfectly from imagination alone. Hippocrates himself reported that obese people more frequently died suddenly and recommended that "they should eat only once a day and take no baths and sleep on a hard bed and walk naked as long as possible." [1] Body mass index (BMI) is a ratio of weight in kilograms divided by height in metres squared $\left(\mathrm{Kg} / \mathrm{m}^{2}\right)$. It is good a predictor for overall health and nutritional status. Obesity is one of the most neglected health problems which lead to cancer, diabetes and cardiovascular disease [2]. Globally, more than 1.9 billion adults are overweight and 650 million are obese. Approximately 2.8 million deaths are reported as a result of being overweight or obese. Overweight and obesity have become a major public health problem in both developing and developed countries. India is a developing country which is in a transitional state of under nutrition due to poverty and obesity due to the industrialization and rapid urbanization. In India, more than 135 million individuals were affected by obesity. Previously, different studies were reported which after using different methodologies and cut off points for defining obesity that created complications in comparison. Presently there is no collective data of prevalence of obesity in India. So, that the present study represents the prevalence of general obesity in India on the basis of studies reported during last 20 years.

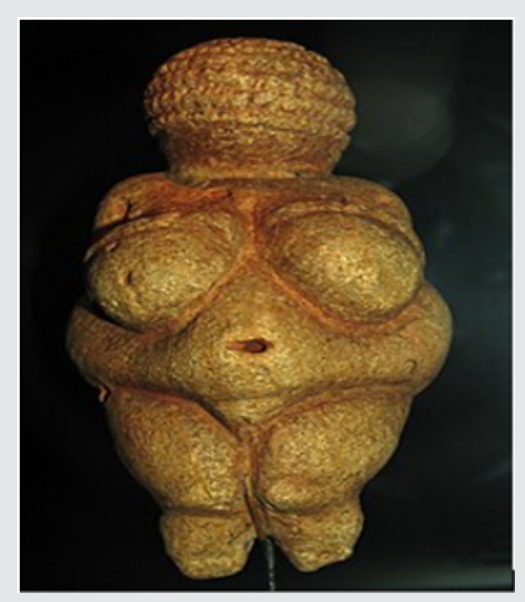

Figure 1: Venus of Willendorf. Paleolithic carving in oolitic limestone from about 25,000 BCE. Wellcome Library, London. 


\section{Criteria for Screening Obesity}

a) WHO criteria for screening obesity for Asian population [3]- Men $\mathrm{WC}=85 \mathrm{~cm}$; $\mathrm{WHR}=0.90$; and Women $\mathrm{WC}=80 \mathrm{~cm}$; $\mathrm{WHR}=0.80$

BMI $\left(\mathrm{Kg} / \mathrm{m}^{2}\right): \quad$ Underweight $=<18.5 ; \quad$ Normal = 18.5-22.9; Overweight $=23.0-24.9 ; \quad$ Obesity $\quad \mathrm{I}=25.0-29.9 ; \quad$ Obesity II $\geq 30.0$.

b) NHLBI Obesity Education Initiative, 2000 [4]- BMI (Kg/ $\mathrm{m} 2$ ): Underweight $<18.5$; Normal $=18.5-24.9$; Overweight $=25$ 29.9; Obesity I = 30-34.9; Obesity II = 35-39.9; Extreme obesity III $\geq 40$.

\section{Obesity and the indian scenario}

Major national survey i.e. national family health survey-4 (NFHS-4) [5] reported that socioeconomically backward states (i.e. Jharkhand, Bihar, Madhya Pradesh and Chhattisgarh) having low rate of prevalence of obesity as compared to higher socioeconomic states (i.e. Punjab (Chandigarh), Goa, Delhi, Andhra Pradesh, Telangana, Puducherry and North east states). The survey revealed that the urban population were at higher risk of obesity as compared to rural population [6]. Studies on tribal population reported higher risk of obesity [7]. In Uttarakhand region reported more than $50 \%$ obesity in both the sexes which is higher than the previous NHFS-4 [8-10] reported. ICMR INDIAB, 2015 conducted a study among rural and urban populations of four major states (i.e. Chandigarh, Maharashtra, Tamil Nadu and Jharkhand) and reported high obesity rate in Chandigarh and lowest in Jharkhand [11]. A high prevalence of obesity of more than $40 \%$ was seen among Marwari community which is a socioeconomically well-established community [12]. According to NCD risk factor surveillance obesity in South India was reorted to be higher (i.e. 27.2\%) followed by North India (i.e. 23.8\%) and lowest in West India (i.e. 15\%) [13]. The NFHS-4 study in 1998 reported 10\% of prevalence of obesity in Andhra Pradesh which is increased to more than 33\% among both the sexes indicating that with the modernization the prevalence of obesity is also increased more than 3 times. There is huge evidence of literature which indicated that women were the prime victim of obesity compared to men.

\section{Methodology}

Participants: All the 4280 new patients visited Cochin Cancer Research Centre for cancer treatment from November 2016 to October 2019. The ethics committee of the Cochin Cancer Research Centre advised that no prior approval is required for analysis of routine data in April 2017.

Materials: Body mass index (BMI) of each patient was meticulously recorded by the Department of nursing and compiled by the medical social workers on registration at the Cochin Cancer Research Centre using the Quetelet Index.

Quetelet Index = body weight (kilograms) divided by height squared $($ meters $)=$ BMI.

Design: Descriptive study
Method: An analysis of the BMI registers at the Cochin Cancer Research Centre from December 2016 to September 2019 showed that:

a) $50 \%$ of patients had normal body weight.

b) $15 \%$ of patients were overweight.

c) $18 \%$ of patients were obese.

d) $10 \%$ of patients were underweight.

\section{Discussion}

\section{What causes obesity?}

Overweight and obesity are the result of chronic energy imbalance. When caloric intake exceeds caloric expenditure, excess energy is stored in the form of adipose tissue, and subsequently body mass is increased. Adipose tissue was once believed to be an inert physiologic buffer to store excess energy. However, adipose tissue is now recognized as an active endocrine organ that promotes multiple physiologic changes that influence disease risk. As the mass of any object can only increase if the energy put into it is greater than the energy lost from it, then attention has obviously been paid to changes in the environment that acted to promote caloric ingestion and those that have acted to diminish the expenditure of energy. In brief, until about the past 50 years, never in the course of history have the majority of humans had such continuous access to sufficient ingestible calories at a time when they did not require a large expenditure of energy to acquire them. There are many powerful influences that together have acted to encourage caloric intake. Ingestible calories are cheaper than ever before in human history [14]. The percentage of household income spent on food has progressively decreased, much of this decrease being attributable to advances in food production, packaging, refrigeration and transport [15].

Ingestible calories have been made more desirable and attractive through food advertising, higher sugar and fat content, and a sophisticated industry that has cleverly used sensory science to encourage purchase and consumption of food. What is presented as a "standard" portion has risen dramatically in size over a relatively short period [16]. Some people are resistant to the obesogenic environment while some are susceptible. It is possible, of course, that all of those who remain lean are making conscious choices to restrain their food intake and increase their expenditure to obtain the social, economic and health benefits that leanness brings. It is also possible that those who are resistant to the obesogenic environment are somehow different in their biological makeup. So, a somewhat tongue-in-cheek question is the following: are lean people 'morally superior' or are they 'biologically different'? Of course, few things in biology are black and white and it is likely that both biological predisposition and conscious exertion of choice both impact on a person's state of adiposity at any particular time [17].

\section{Obesity and Breast cancer}

There is a large body of evidence supporting an association between obesity and an increased risk of breast cancer recurrence 
and death. Obesity is a risk factor for complications after mastectomy $[18,19]$, either alone or in combination with immediate breast reconstruction, whether implant based or autologous [18-20]. Complications include surgical site complications viz., infections, wound dehiscence, and prosthetic and flap loss, and, systemic medical complications viz., venous thromboembolism (VTE) and pneumonia. Morbidly obese patients (Class III; BMI $>40 \mathrm{~kg} / \mathrm{sq} \mathrm{m}$ ) are at particularly elevated risk for these complications [21]. Risk of VTE in obese patients is procedure dependent, increasing from $0.4 \%$ to $0.8 \%$ to $1.8 \%$ for mastectomy to implant to autologous reconstruction [22]. Obesity is also a risk factor for lymphoedema after breast cancer surgey, with risk estimates up to 5.5-fold higher [23]. This information can be incorporated into surgical risk counselling and management; for instance, the incidence of VTE after implant-based reconstruction is approximately $1 \%$ and that after autologous reconstruction is approximately $2 \%$, so consideration of prophylactic anticoagulants may be reasonable. Obese patients with cancer should receive full weight-based chemotherapy doses calculated using their actual body weight, especially when the goal is cure $[24,25]$. There is no evidence to suggest increased haematologic or nonhematologic toxicity with such dosing.

In contrast, there is evidence to support poorer survival outcomes (DFS,OS) with underdosing of chemotherapy. In the event of dose reductions, consideration for resumption of full weight-based dosing should be the same as those for nonobese patients. Fixed dosing (independent of body weight or BSA) should be considered for certain chemotherapy agents (eg. carboplatin). Overweight and obesity have recently been associated with higher risk of cardiotoxicity after treatment with trastuzumab in women with HER2-positive breast cancer [26]. Close monitoring and effective management of cardiac risk factors (eg. blood pressure, cholesterol, smoking) should be considered in these patients. Concerns have been raised about the relationship between BMI and Aromatase Inhibitor (AI) adjuvant therapy benefit. Available evidence suggests that anastrozole may be associated with inferior outcomes (v tamoxifen) in both post- and premenopausal patients who are obese; this was not found to be true for letrozole ( $v$ tamoxifen) in postmenopausal obese patients [27-29]. For postmenopausal patients, data from the BIG 1-98 trial (Breast International Group 1-98 trial) support use of letrozole and data from ATAC and ABCSG-6a trials raise concerns regarding use of anastrozole. As a result, because of potentially increased efficacy but equivalent tolerability, it is reasonable to use letrozole rather than anastrozole in obese postmenopausal patients. For premenopausal patients, the current standard of care from TEXT (Tamoxifen and Exemestane Trial) and SOFT (Suppression of Ovarian Function Trial) trials is to use exemestane plus ovarian suppression when indicated for aggressive disease; in the absence of further evidence to the contrary, this is acceptable for obese patients[30,31].

Although obesity is associated with poor outcomes in women with breast cancer, it is not clear whether postdiagnosis weight loss (resulting from changes in caloric intake, physical activity, or other interventions) will reverse this effect. There are several potential reasons for this. It remains possible that obesity is not causally associated with outcomes; in this case, weight loss will not affect outcomes. If obesity is causally associated with outcomes, biologic effects of obesity may be fixed at diagnosis (ie, obese women may have more proliferative or aggressive tumours, characteristics that may not change with weight loss). Alternatively, the degree of weight loss possible with available lifestyle interventions (typically $5 \%$ to $7 \%$ ) may not be sufficient to alter outcomes [32,33].

\section{Obesity and Gastrointestinal Cancer}

Many patients with GI cancer who are overweight or obese have comorbid health conditions such as cardiovascular and cerebrovascular disease, diabetes, and metabolic syndrome at the time of diagnosis, which may influence treatment decision making. Although surgery may be more complex in overweight/obese patients [34], with few exceptions, primarily at the extremes, postoperative morbidity rates and incidence of complications are often similar to those of normal-weight patients [35]. Full weight-based systemic therapy should be used when treating obese patients [36], because rates of toxicity are similar or lower among obese patients compared with normal-weight patients $[37,38]$. Oncology providers should encourage consumption of a balanced and healthy diet, at least weight maintenance and possibly weight loss in obese patients, physical activity, and reduction of sedentary behaviours (eg. television and computer use, prolonged sitting). These recommendations are consistent with clinical practice guidelines for patients with cancer [39-42]. Dietary recommendations include a diet pattern that is high in vegetables, fruits and whole grains[40], and avoid a western pattern diet that is characterized by frequent consumption of red and processed meats, sugar desserts and sugarsweetened beverages, and refined grains [43].

The use of meal replacement products, including packaged entrees and shakes [44], or referral to commercial weight loss programmes may be useful to promote initial weight loss for survivors of disease sites where overweight or obesity are associated with outcomes [45]. Patients should participate in regular physical activity towards the volume goal of a minimum of 150 minutes per week of moderate-intensity aerobic activity $[40,41]$. However, any volume of physical activity that a patient can do should be considered better than sedentary behaviour [41]. Many patients will elect to use walking as their primary modality of activity. For these patients, a walking cadence of 100 steps per minute is consistent with moderate intensity for most adults [46]. Activity should be accumulated in bouts of $>/=10$ minutes; the use of a pedometer is encouraged to quantify step counts, and 1,000 steps in 10 minutes or 3,000 steps in 30 minutes is a useful mnemonic to guide patients. Higher volumes of regular physical activity (250 to 300 minutes per week) may be required for the prevention of weight regain. Patients with physical impairments that may serve as a barrier or make it unsafe to engage in physical activity [47] should be referred to trained rehabilitation health care professionals [48].

\section{Obesity and Endometrial cancer}

In sharp contrast to many other cancer types, the incidence and mortality of endometrial cancer continue to grow. This unfortunate trend is, in no small part, a result of the worldwide obesity epidemic. 
More than half of endometrial cancers are currently attributable to obesity, which is recognized as an independent risk factor for this disease. Women diagnosed with endometrial cancer or complex atypical hyperplasia ( $\mathrm{CAH})$, a precursor lesion to endometrial cancer being obese portends worse outcomes. Obesity contributes to the increased risk of endometrial cancer in the postmenopausal uterus by a variety of mechanisms. Visceral fat is a complex endocrine organ, composed of adipocytes and preadipocytes, as well as infiltrating macrophages, stromal, nerve, and stem cells. Together, they secrete an array of adipokines that exert local and systemic effects, which increase endometrial proliferation and promote tumorigenesis [49-52]. In premenopausal women, the cyclic expression of oestrogen by the ovaries drives endometrial proliferation. After menopause, peripheral tissues, especially adipose tissue, become the main site of oestrogen synthesis. Furthermore, adipose tissue is a source of mesenchymal stem cells, which can be recruited to support tumour growth and progression $[53,54]$.

Interventions for the prevention of endometrial cancer include potential lifestyle interventions and surgical procedures that decrease visceral adiposity, as well as medications that aim to interrupt or reverse the hormonal and metabolic derangements associated with obesity and insulin resistance. Robotic surgery may offer advantages over traditional laparoscopy in women with increasing BMI as it is associated with longer operating times and an increased risk of postoperative morbidity. The total number of surgical complications was highest among morbidly obese patients who underwent laparotomy. It is estimated that approximately $10 \%$ of patients with early stage endometrial cancer are medically inoperableas a result of obesity-related medical comorbidities, such as cardiovascular disease and diabetes-related end-organ damage [55]. These patients can be managed with primary radiation therapy. A recent consensus statement from the American Brachytherapy Society recommends that women with inoperable clinical stage I endometrial cancer undergo imaging with magnetic resonance imaging (MRI). Women with no apparent lymph node involvement or deep myometrial invasion on MRI may be managed with brachytherapy alone. If these factors are present or no MRI imaging is performed, a combined approach with external-beam radiation and brachytherapy should be considered [56]. As obesity among young women continue to increase, oncologists are seeing younger women with endometrial cancer. Ovarian conservation at the time of surgery and the use of fertility-sparing treatments impact clinical management.

\section{Obesity and Renal cancer}

There is an obesity paradox in patients with Renal cell carcinoma with the clear cell variant. That is, although obesity is an established risk factor for renal cell carcinoma, being obese at diagnosis seems to be associated with a favourable outcome compared with the outcomes of patients with normal weight at diagnosis [57]. Some studies have reported that obese patients are more likely to be diagnosed with favourable clinical characteristics, including lower stage disease, lower Fuhrman grade, and smaller tumours, compared with normal-weight patients [58]. Further support from gene expression analyses demonstrates that obese patients are less likely to have a tumour with fatty acid synthase (FASN), which encodes the proteins necessary for tumour growth [59].

\section{Obesity and other cancers}

There is no clear link between obesity and overall prostate cancer incidence. A growing body of research indicates that obesity is associated with worse pathologic outcomes in prostate cancer; however, evidence of an association has varied across cohort studies [60]. Epidemiologic studies show that obesity is associated with an increased risk of prostate cancer aggressiveness, progression, and cancer-specific mortality [61]. Although physical activity, especially vigorous activity, is inversely related to the incidence of aggressive prostate cancer and may also be associated with a decreased overall incidence of prostate cancer, in an analysis of asian cohorts associations between obesity and prostate cancer seem to be independent of the level of physical activity[62].

Epidemiologic evidence from prospective cohort studies indicates dose-response associations between excessive bodyweight and an increased risk of mortality from several subtypes of haematologic malignancies especially multiple myeloma and Non-Hodgkin's Lymphoma (NHL) and Diffuse Large B Cell Lymphoma [63]. Across these studies, a worse prognostic outcome in underweight patients was reported, consistent with the impact of the disease process on weight [64-66]. Current evidence suggests a modest but consistent direct effect of BMI on poor prognostic outcomes in lymphoma, multiple myeloma, and leukaemia [67]. Risk increases in a dose-response manner in several subtypes of haematologic malignancies. It is also important to note that the adverse impact of BMI on multiple myeloma prognosis may reflect aetiologic risk that starts growing early, during young adulthood $[68,69]$. Separating the aetiologic effect, disease severity at diagnosis, and outcomes requires more evidence from randomized interventions. To date, the small number of prospective studies and the lack of adjustment for possible confounding factors such as treatment, smoking, and comorbidities may bias the estimates reported for mortality as a result of haematologic malignancies.

\section{Conclusion}

The role of governmental policies, laws and regulations in preventing the obesity epidemic Obesity is currently attracting public and political attention, but this may not be a lasting phenomenon. Indeed, the stigma associated with being obese means that the public constituency agitating for change is quite small. There is not a groundswell of overweight and obese people calling for action - the pressure is predominantly coming from the professional sector. This makes obesity a commercial success but a market failure. Even though legislation for obesity prevention could not be directly aimed at eating and physical activity behaviours, any 'rule-based' approach (even at the level of school or home rules) is likely to be a powerful way of changing social norms and attitudes. For example, a policy banning high fat or sugar food and beverages from school canteens can be expected to accelerate the transition in norms from canteens full of foods high in fat, sugar and 
salt to canteens with foods that match those promoted in school's nutrition curriculum.

While only a few percent of children's total yearly energy intake come from the school canteen, having visible icons of healthy food are likely to be very important in influencing eating patterns outside school, and show children and parents the way forward for healthy eating. Government policy leadership will be needed to accelerate effective action to reduce obesity and its associated inequalities. The suite of interventions will have to include some 'hard paternalism' policy options such as legislation and regulation to make human environments less obesogenic. The calls for action from public health and community advocates are strong. When real political leadership is added to the mix, real progress can be made. The data presented from the Cochin Cancer Research Centre is a bird's eye view to the obesity burden of Kerala State in India.

\section{References}

1. Bray GA (1990) Obesity: historical development of scientific and cultural ideas. Int J Obes14: 909-926.

2. (2014) Global status report on non-communicable diseases 2014 .

3. (2011) World Health Organization -Waist circumference and waist-hip ratio: report of a WHO expert consultation, Geneva, 8-11 December 2008.

4. National Institutes of Health, North American Association for the Study of Obesity. The Practical guide: identification, evaluation, and treatment of overweight and obesity in adults (2000). NIH Publication Number 004084

5. (2018) National Family Health Survey, India. Key findings (2015-16).

6. Mishra D, Naorem k, Saraswathy KN (2018) Angiotensin-converting enzyme gene insertion/deletion polymorphism and cardiometabolic risk factors: a study among Bhil tribal population from two environmental settings. Biochem Genet 56(4): 295-314.

7. Ningombam SS, Chhungi V, Newmei MK, Rajkumari S, Devi NK, et al (2018) Differential distribution and association of FTO rs9939609 gene polymorphism with obesity: a cross-sectional study among two tribal populations of India with East-Asian ancestry. Gene, 647: 198-204.

8. Kandpal V, Sachdeva MP, Saraswathy KN (2016) An assessment study of CVD related risk factors in a tribal population of India. BMC Public Health 16 (1): 434

9. Joshi SR, Anjana RM, Deepa M, Pradeepa R, Bhansali A, et al. (2014) Prevalence of dyslipidemia in urban and rural India: the ICMR-INDIAB study. PLoS One 9 (5): e96808.

10. Kumar A, Kalra S, Unnikrishnan AG (2016) Metabolic state of the nation: results of the national family health survey-4. Indian J Endocrinol Metabol 20 (4):429-431.

11. Pradeepa R, Anjana RM, Joshi SR, Bhansali A, M Deepa, et al. (2015) Prevalence of generalized \& abdominal obesity in urban \& rural Indiathe ICMR-INDIAB Study (Phase-I)[ICMR-INDIAB-3]. Indian J Med Res142 (2):139-1350.

12. Das M, Bose K (2006) Presence of high rates of overweight and obesity among adult Marwaris of Howrah, West Bengal, India. Coll Antro pol 30(1): 81-86.

13. Mohan V, Mathur p, Deepa R, Deepa M, Shukla DK, et al. (2008) Urban rural differences in prevalence of self-reported diabetes in India-the WHO-ICMR Indian NCD risk factor surveillance. Diabetes Res Clin Pract $80(1): 159-168$

14. (2015) Department for Environment, Food and Rural Affairs, National Statistics. Family food 2014. London: DEFRA.
15. Drewnowski A, Darmon N (2005) The economics of obesity: dietary energy density and energy cost. Am J Clin Nutr 82: 265S-73S.

16. Young LR, Nestle M (2003) Expanding portion sizes in the US marketplace: implications for nutrition counselling. J Am Diet Assoc 103: $231-240$.

17. Llewellyn C,Wardle J (2015) Behavioural susceptibility to obesity: Geneenvironment interplay in the development of weight. Physiol Behav 152: 494-501.

18. Fischer JP, Tuggle CT, Au A (2014) A 30-day risk assessment of mastectomy alone compared to immediate breast reconstruction (IBR). J Plast Surg Hand Surg 48: 209-215.

19. Jeevan R, Browne JP, Pereira J (2015) Socio-economic deprivation and inpatient complication rates following mastectomy and breast reconstruction surgery. Br J Surg 102: 1064-1070.

20. Fischer JP, Nelson JA, Kovach SJ (2013) impact of obesity on outcomes in breast reconstruction: Analysis of 15,937 patients from the ACS-NSQIP datasets. J Am Coll Surg 217: 656-664.

21. Fischer JP, Cleveland EC, Nelson JA (2013) Breast reconstruction in the morbidly obese patient: Assessment of 30-day complications using the 2005 to 2010 National Surgical Quality Improvement Program data sets. Plast Reconstr Surg 132: 750-761.

22. Fischer JP, Wes AM, Tuggle CT (2014) Venous thromboembolism risk in mastectomy and immediate breast reconstruction: Analysis of the 2005 to 2011 American College of Surgeons National Surgical Quality Improvement Program data sets. Plastic Reconstr Surg 133: 263e-273e.

23. DiSipio T, Rye S, Newman B (2013) Incidence of unilateral arm lymphoedema after breast cancer: A systematic review and metaanalysis. Lancet Oncol 14: 500-515.

24. Griggs JJ, Mangu PB, Anderson H (2012) Appropriate chemotherapy dosing for obese adult patients with cancer: American Society of Clinical Oncology clinical practice guideline. J Clin Oncol 30: 1553-1561.

25. Lyman GH, Sparreboom A (2013) Chemotherapy dosingin overweightand obese patients with cancer. Nat Rev Clin Oncol 10: 451-459.

26. Mantarro S, Rossi M, Bonifazi M (2016) Risk of severe cardiotoxicity following treatment with trastuzumab: A meta-analysis of randomized and cohort studies of 29,000 women with breast cancer. Intern Emerg Med 11: 123-140.

27. Sestak I, Distler W, Forbes JF (2010) Effect of body mass index on recurrences in tamoxifen and anastrozole treated women: an exploratory analysis from the ATAC trial. J Clin Oncol 28: 3411-3415.

28. Bhatnagar AS (2007) The discovery and mechanism of action of letrozole. Breast Cancer Res Treat 105: 7-17.

29. Lonning PE (2011) The potency and clinical efficacy of aromatase inhibitors across the breast cancer continuum. Ann Oncol 22: 503-514.

30. Pagani O, Regan MM, Walley BA (2014) Adjuvant exemestane with ovarian suppression in premenopausal breast cancer. N Engl J Med 371: 107-118.

31. Francis PA1, Regan MM, Fleming GF, Láng I, Ciruelos E, et al. (2015) Adjuvant ovarian suppression in premenopausal breast cancer 372(5): 436-446.

32. Rock CL, Doyle C, Demark Wahnefried W (2012) Nutrition and physical activity guidelines for cancer survivors. 62(4): 243-274.

33. Runowicz CD, Leach CR, Henry NL (2016) American Cancer Society/ American Society of Clinical Oncology breast cancer survivorship care guideline. 34(6): 611-635.

34. Curet MJ (2000) Special problems in laparoscopic surgery Previous abdominal surgery, obesity, and pregnancy. Surg Clin North Am 80(4): 1093-1110.

35. Dindo D, Muller MK, Weber M (2003) Obesity in general elective surgery. Lancet 361(9374) : 2032-2035. 
36. Griggs JJ, Mangu PB, Anderson H (2012) Appropriate chemotherapy dosing for obese adult patients with cancer: American Society of Clinical Oncology practice guideline 30(13): 1553-1561.

37. Meyerhardt JA1, Catalano PJ, Haller DG, Mayer RJ, Benson AB 3rd, et al. (2003) Influence of body mass index on outcomes and treatmentrelated toxicity in patients with colon carcinoma. 98: 484-495.

38. Meyerhardt JA1, Tepper JE, Niedzwiecki D, Hollis DR, McCollum AD, et al. (2004) Impact of body mass index on outcomes and treatment-related toxicity in patients with Stage II and III rectal cancer: Findings from Intergroup Trial 0114.22(4): 648-657.

39. Ligibel JA, Alfano CM, Courneya KS, Demark-Wahnefried W, Burger RA et al. (2014) American Society of Clinical Oncology position statement on obesity and cancer. J Clin Oncol 32(31): 3568-3574.

40. Rock CL, Doyle C, Demark Wahnefried W (2012) Nutrition and physical activity guidelines for cancer survivors. CA Cancer J Clin 62(4): 243-274.

41. Schmitz KH, Courneya KS, Matthews C (2010) American College of Sports Medicine roundtable on exercise guidelines for cancer survivors 42(7): 1409-1426.

42. Denlinger CS, Ligibel JA, Are M (2014) Survivorship: Healthy lifestyles. 12(9): 1222-1237.

43. Meyerhardt JA1, Niedzwiecki D, Hollis D, Saltz LB, Hu FB, et al. (2007) Association of dietary patterns with cancer recurrence and survival in patients with stage III colon cancer. 298(7): 754-764.

44. Befort CA, Klemp JR, Austin HL, et al. (2012) Outcomes of a weight loss intervention among rural breast cancer survivors. 132(2): 631-639.

45. Gudzune KA, Doshi RS, Mehta AK (2015) Efficacy of commercial weightloss programs: An updated systematic review 162(7): 501-512.

46. Marshall SJ, Levy SS, Tudor-Locke CE, et al. (2009). Translating physical activity recommendations into a pedometer-based step goal: 3000 steps in 30 minutes. 36(5): 410-415.

47. Brown JC, Schmitz KH (2014) The prescription or proscription of exercise in colorectal cancercare. 46(12): 2202-2209.

48. Silver JK, Baima J, Mayer RS (2013) Impairment-driven cancer rehabilitation: An essential component of quality care and survivorship. 63(5): 295-317.

49. Renehan AG, Zwahlen M, Egger M (2015) Adiposity and cancer risk: New mechanistic insights from epidemiology.15(8): 484-498.

50. Alliott EH, Hursting SD (2015) Obesity and cancer: Mechanistic insights from transdisciplinary studies. 22(6): R365-R386.

51. Park J, Morley TS, Kim M (2014) Obesity and cancer: Mechanisms underlying tumour progression and recurrence. 10(8): 455-465.

52. Khandekar MJ, Cohen P, Spiegelman BM (2011) Molecular mechanisms of cancer development in obesity.11(12): 886-895.

53. Klopp AH, Zhang Y, Solley T (2012) Omental adipose tissue-derived stromal cells promote vascularization and growth of endometrial tumors. Clin Cancer Res ;18(3): 771-782.
54. Pope BD, Warren CR, Parker KK (2016) Microenvironmental control of adipocyte fate and function. Trends Cell Biol;26(10): 745-755.

55. Acharya S, Esthappan J, Badiyan S (2016) Medically inoperable endometrial cancerin patients with a high body mass index(BMI):Patterns of failure after 3-D image-based high dose rate(HDR) brachytherapy. Radiother Oncol;118(1): 167-172.

56. Schwarz JK, Beriwal S, Esthappan J (2015) Consensus statement for brachytherapy for the treatment of medically inoperable endometrial cancer. Brachytherapy; 14(5): 587-599.

57. Donin NM, Pantuck A, Klopfer P (2016) Body mass index and survival in a prospective randomized trial of localized high-risk renal carcinoma. Cancer Epidemiol Biomarkers Prev;25(9): 1326-1332.

58. Choi Y, Park B, Jeong BC (2013) Body mass index and survival in patients with renal cell carcinoma: A clinical based cohort and meta-analysis. Int J Cancer; 132(3): 625-634.

59. Hakimi AA, Furberg H, Zabor EC (2013) An epidemiologic and genetic investigation into the obesity paradox in renal cell carcinoma. J Natl Cancer Inst 105(24): 1862-1870.

60. MacInnis RJ, English DR (2006) Body size and composition and prostate cancer risk: Systematic review and meta-regression analysis. Cancer Causes Control 17(8): 989-1003.

61. Allott EH, Masko EM, Freedland SJ (2013) Obesity and Prostate Cancer: Weighing the evidence. Eur Urol 63(5): 800-809.

62. Fowke JH, McLerran DF, Gupta PC (2015) Associations of body mass index, smoking and alcohol consumption with prostate cancer mortality in the Asia Cohort Consortium. Am J Epidemiol 182(5): 381-389.

63. Renehan AG, Tyson M, Egger M (2008) Body mass index and incidence of cancer: A systematic review and meta-analysis of prospective observational studies. Lancet 371(9612): 569-478.

64. Hwang HS, Yoon DH, Suh C (2015) Body mass index as a prognostic factor in Asian patients treated with chemoimmunotherapy for diffuse large B cell lymphoma, not otherwise specified. Ann Hematol 94(10): 1655-1665.

65. Park S, Han B, Cho JW (2014) Effect of nutritional status on survival outcome of diffuse large B-cell lymphoma patients treated with rituximab-CHOP. Nutr Cancer 66(2): 225-233.

66. Navarro WH, Loberiza FR, Jr., Bajorunaite R (2006) Effect of body mass index on mortality of patients with lymphoma undergoing autologous hematopoietic cell transplantation. Biol Blood Marrow Transplant 12(5): 541-551.

67. Rodriguez-Abreu D, Bordoni A, Zucca E (2007) Epidemiology of haematological malignancies. Ann Oncol 18(Suppl1): i3-i8.

68. Wallin A, Larsson SC (2011) Body mass index and risk of multiple myeloma: A meta-analysis of prospective studies. Eur J Cancer 47(11): 1606-1615.

69. Teras LR, Kitahara CM, Birmann (2014) Body size and multiple myeloma mortality: A pooled analysis of 20 prospective studies. Br J Haematol 166(5): 667-676. 
CC (i) This work is licensed under Creative Commons Attribution 4.0 License

To Submit Your Article Click Here: Submit Article

DOI: $10.32474 /$ RRHOAJ.2019.04.000184

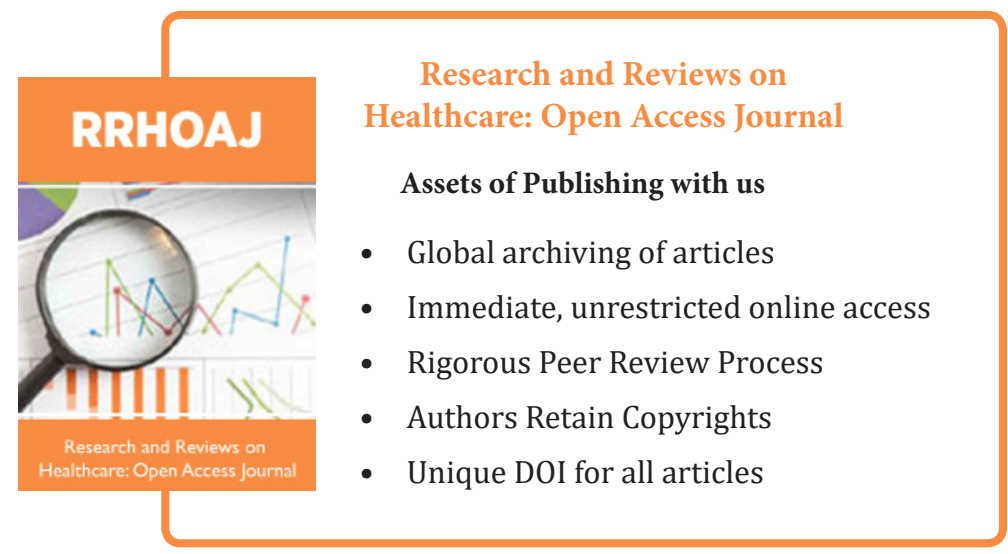

